Article

\title{
More than Just Food: Food Insecurity and Resilient Place Making through Community Self-Organising
}

\author{
Megan K. Blake $\mathbb{D}$ \\ Department of Geography, University of Sheffield, Sheffield S10 2TN, UK; m.blake@sheffield.ac.uk
}

Received: 25 March 2019; Accepted: 20 May 2019; Published: 23 May 2019

check for updates

\begin{abstract}
This research considers the relationship between neoliberalism, poverty and food insecurity and how this impacts on the ability of a community to self-organise and become resilient. Specifically, it examines shocks imposed by the implementation of austerity policy and neoliberal welfare reform and the longer term individualisation that gives rise to greater vulnerability to such shocks and how community organisations encourage different levels of resilience in the face of this. Original findings from case study and qualitative analysis are twofold. Firstly, food insecurity effects are not only hunger and poor health experienced at the individual scale, but they also extend into places through the loss of social networks, erosion of community spaces, denigration of local foodscapes and collective de-skilling that limits the community resources needed for self-organising. Secondly, the ways in which food support is provided in communities has implications for how communities can regain the resources they need to be able to enact resilience in the face of trouble and difficulty. As such, the research demonstrates that self-organising is more than free-time activity; in these conditions, the capacity to self-organise is a vital community asset that is necessary for building resilience and social sustainability. As such, policy responses to poverty should take a multi-scale approach.
\end{abstract}

Keywords: food insecurity; resilience; community; food poverty; austerity; neoliberalism; UK

\section{Introduction}

This paper examines the recursive relationships between neoliberalism's undermining of community resources and the consequential ability and practices of differently placed community-based organisations that emerge to seek to buttress and rebuild—rather than simply backfill—those community resources. This examination is undertaken through a practice approach, which places doings and sayings in an interconnected web with material and institutional contexts, social norms, and community and individual orientation, understanding and capacity [1]. To make its argument, the article takes the case of food-insecurity in predominantly low-income communities situated in a wealthy national context characterised by its neoliberal political-economy, specifically the United Kingdom. The paper reveals that although the ability of low-income communities for self-organising is being undermined by neoliberalism, heretofore under-researched combinations of food-using activity can shape local communities' capacities for the necessary self-organisation of their community resources that when mobilised help to reduce the vulnerabilities of food insecurity.

To make this argument, the paper proceeds in the following order. In the remainder of this introduction, the theoretical grounding of the argument is first introduced. This is followed by a discussion of food insecurity as it intersects with the UK neoliberal context. The following section outlines the intensive qualitative methodology utilised in this research to understand how the process by which community assets are enhanced or undermined. The paper then turns to a combined results and discussion section. The first part of this section considers how the capacity of those who are food insecure as a result of poverty undermines the wider community ability to self-organise and limits the resilience of households and the community more generally. The latter part of this section 
interrogates the potential for mobilising food-using activities as a means for enhancing and rebuilding self-organising community capacity. The final part of the section draws the discussion back to the necessary and vital role that self-organising plays in building resilience, but contends that it is not a sufficient condition for overcoming food insecurity in low-income communities.

\subsection{Resilience and Capacity for Community Self-Organisation}

Resilience has risen in the academic and policy agendas in recent years, partly in response to a context of on-going austerity and service cuts in which coping as individuals and communities with diminished resources has become the necessary norm [2]. A key to building and maintaining resilience in communities is self-organisation [3]. Self-organising systems are based on bottom-up, independent (non-state) actions of multiple agents within the system and do so in accommodative, collaborative ways [4]. Research has identified the characteristics of self-organised activity as including voluntary mutual accommodation and interdependent enterprise that benefits those who are involved individually as well as the community as a whole [5]. A further characteristic is the adaptive capacity of the system when there are changes to the wider context within which it sits [4]. In other words, there is a necessary relationship between self-organising and the ability of communities to be able to sustain themselves through periods of shock. If we consider self-organising as something that is done, rather than just as a set of characteristics, it becomes clear that in order to perform self-organising, there must also be resources that facilitate and feed that practice. Resources include the individually based (income, mental and physical health and capacity), place-based (physical aspects of a place such as shops and social space, local authority budgets and services), and relationally based (social connections, feelings of safety, etc.) assets that are present in locations [6,7]. Those who are potential participants must have the capacity to participate and to recognise and mobilise resources; something research demonstrates is more likely to be the case in affluent communities compared to deprived communities [8]. What is less clear in existing research is how wider macro-level neoliberal contexts in which communities are embedded shape the capacity for community self-organisation.

This research adopts a framework that posits that resilient self-organisation is a practice that is influenced by wider political, economic systems. This approach starts from the position that the social systems that help to order everyday life are dynamic and complex. Furthermore, these systems emerge not just as a result of policy interventions that solidify into institutions but also through the ongoing everyday practices of doing, being and saying as they play out in the time-spaces of everyday life [1]. Within this framework, doing and being resilient in a particular context is a process of learning to identify and mobilise the resources needed to adapt to and overcome shocks to avoid crises, or when crises occur to be able to recover from them [9]. Moreover, as skill and other resources increase so should the ability to become successful at navigating and influencing system change, such that vulnerability to shock is dampened down [10]. In the context of resilience-focused community self-organising, practices are enacted toward ends that aim to achieve further outcomes, such as the ability to cope with the current condition, to adapt to shocks that may arise or to transform the degree to which vulnerability is present in the first instance (see [11] for a discussion of coping and transformation as outcomes of resilience). In the context of food insecurity, this could include enabling households to cope in the short term with food insecurity or by creating mechanisms and infrastructures that can be readily mobilised to mitigate against shocks such as job loss or food price increases that increase vulnerability to food insecurity.

The contributions of this practice-based approach when turned toward understanding how community self-organised resilience building can help address food insecurity are twofold. Firstly, the approach highlights the effects of neoliberalism and austerity on those resources that are necessary for self-organised resilience practices to be successfully undertaken, but which are frequently neglected in the literature. Secondly, it opens up new avenues for understanding how to support individuals within highly deprived communities to be able to self-organise. The research reveals a range of previously invisible practices that seek to make food accessible, to rebuild community adaptability, and to alter 
existing local foodscapes [12,13]. As such, the empirical account also addresses an existing lacuna in our understanding of food support in low-income communities, which largely focuses on emergency food provision (food banks) and its relationship with immediate crisis (e.g., [14,15]), and for non-UK contexts also see [16-18]). The research also identifies that policy promoting self-organising as the whole solution to food insecurity is making unreasonable expectations on individuals and in communities that have been hollowed out by austerity and welfare reforms. At the same time, simple roll-back solutions that focus only on redressing financial need are also insufficient as they do not build-up those other resource deficits that are created by neoliberalism and austerity.

\subsection{The UK Neoliberal Context}

The relationship between poverty and food insecurity is not a necessary one, but in the UK, a neoliberal governance context enables the two to form a contingent relationship that is creating hardship. The United Kingdom is currently ranked as having the seventh largest economy globally [19] At the same time, one-fifth of its people are living with incomes at or below poverty. This is calculated as an income below $60 \%$ of the median national income when housing costs are considered. This is the measure of poverty used by the House of Commons in their Poverty in the UK report [20]. Recent research by Loopstra, Reeves and Tarasuk [21] demonstrates that in the UK the probability that low-income adults will be food insecure rose from $28 \%$ in 2004 to approximately $45 \%$ by 2016, which indicates that shifts in government policy toward a more entrenched neoliberalism have had real implications for the food insecurity of low-income households. Importantly, their research also finds that those low-income households where there are children had a probability of being food insecure of nearly $70 \%$.

According to wide consensus, neoliberalism is considered the "dominant approach to governing human affairs worldwide ([22], (p. 1))". While neoliberal political economic theory was introduced to the UK during the Thatcher period, more recently, since the economic crisis in 2008 it has been more deeply entrenched into government policy. Neoliberal policies are those that seek to maximise profit through market exchange [23], and include interventions such as the implementation or withdrawal of regulations such that market-favourable conditions, withdrawal of community property, and marketisation of the state sector via economic measures such as budget-capping are the outcome [22]. Neoliberalism widens the income divide between the wealthy and the poor as it also withdraws and reconfigures state-sponsored social support and seeks to replace it through the growth of voluntary, charitable, third sector or community groups [22,24].

Implementation of austerity policies and a deeper entrenchment of neoliberalism by the UK government has produced a context characterised by the withdrawal of state infrastructures that provide needed services and spaces in communities [25]. Since 2010, the amount of community development support, children's centres, state-sponsored family programs and advice centres have been withdrawn alongside the closure, abandonment, or selling off of parks, libraries, and village halls leading to a loss of state-sponsored spaces for social interactions. Jones et al. [26] illustrate these cuts have also put community organisation funding under stress as many local authorities in areas that are most deprived have cut voluntary service funding just as demand for the services they provide has increased (see also [25]). As local authority councils report having to cut their budgets on average by $26 \%$, some areas have seen greater cuts as a result of being unable to raise funds locally and which are more likely to be areas where there is considerable income deprivation [27]. Councils also report that in all areas budget spending has decreased with the exception of children's social care, which has increased as a result of increases in the number of children being looked after. Looked-after children are children for whom the council believes the child is suffering or there is risk of severe significant harm if the child remains in their home. These children are placed with foster carers or other family members as a result of a care order issued by a court. Between 2014 to 2018 the numbers of looked-after children have increased by approximately $10 \%$, which represents more children being taken into care now than there were in the 1980s [28]. 
At the same time, welfare reforms have in practice created increased financial uncertainty and hardship for households [29]. These reforms are complex and multiple including shifts in how low-income and disability support is provided, how people may access support and what support entails (see $[25,30]$ for fuller descriptions of individual reforms). A key element of these reforms includes the replacement of Job Seekers allowance with Universal Credit, which includes caps on benefits income, and a five-week delay before the first payment, and conditionalities that if not met can result in sanctions that reduce the amount received. Additionally, rather than individual benefits, benefits are also provided in a single payment and are combined for the whole household. Alongside this, and starting when George Osborne was the Chancellor but extending into the recent budgets including that for 2019, is the fact that the benefits and tax credit payments have been frozen at 2015 values and this is set to continue until 2020. According to Joseph Rowntree Foundation, by 2019 this equated to approximately $£ 340$ less per year or a decrease in income of about $6.5 \%$ because of inflation [31].

Over a more extended period, the increased acceptance of neoliberal ideology has individualised households, such that values of personal choice, individual responsibility and self-reliance are prioritised over values that focus on collective goods such as sharing, fairness and community connectivity [32]. This same ideology and its associated values has also sought to replace infrastructures once provided by the state with a system of self-organised individuals who cooperate in providing these services, also characterised as volunteerism [33,34]. While the UK has long had organisations that aim to address poverty-related vulnerability (e.g., the Salvation Army), since 2010 the UK has seen a rise in locally based initiatives that seek to promote community-led support, which involves new funding and resourcing models and higher incorporation of individual citizen involvement in service delivery (e.g., through volunteers and corporate sponsorship or by facilitating access to donations that help to reduce costs). Importantly, while this research focuses on the UK context, similar increases are also observable in other national contexts where a neoliberal political economy is active as demonstrated by, for example, the rise in initiatives framed as food justice which seek to address issues of food access in neighbourhoods where food access is limited and populations are poor and otherwise disadvantaged in the United States [12,13,35-37].

\section{Materials and Methods}

Because the aim of the research is to understand processes and tease out the complexities that enable or undermine community assets within the context of neoliberalism, an intensive approach drawing on two qualitative case studies augmented by and triangulated with additional qualitative data was employed. Unlike extensive methods, which seek out patterns and try to understand the extent to which a particular phenomenon is present, an intensive qualitative approach seeks to understand processes as they are grounded in the experiences and narratives of those who are directly involved in living with the wider political, economic and social context [38]. Case studies are used in particular because they not only offer the opportunity to develop the deep interrogations that are central to intensive analysis but as argued by Flyvbjerg [39] case studies have a number of advantages. Firstly, case studies provide detailed context-dependent knowledge creation which allows for new avenues to be examined, compared to the more path-dependent understanding and potential for confirmation bias that is endemic to hypothesis testing. Secondly, although generalisations generated through a small number of case studies, because of their context dependency, do not allow us to confirm or reject the extent to which a population responds to a particular set of circumstances, they do allow generalisations about how processes might work or play out while still enabling complexity to be present. In this paper case studies are used in order to build theory focused on how community assets are shaped by neoliberal-policies on the one hand and locally based-community organisations on the other.

To enable an understanding of which systems, processes and practices may be experienced more generally within the UK and those that are specific to the locations and characteristics of these two case 
studies supplementary additional qualitative data was collected. Specifically, this data was mobilised to enable a broadening out of the discussion concerning the effects of food insecurity on the strength of community assets. This additional data collection is described below. Prior to this, the case studies are discussed.

\subsection{Case Studies}

The communities and households that are served by two case study community-based organisations form the majority of the research data for this paper. The first is a locally-based community voluntary organisation (Organisation A) and the second is a community interest company (CIC) that has five locations across England and is affiliated with a for-profit food business (Organisation B). Cases were selected strategically to enhance their ability to inform generalisations concerning community-based resilience building [39]. Considerable time was spent with both organisations in order to build trust with participants and to establish rapport. Repeated visits to the organisations also allowed opportunities to follow up on hunches and observations and cross-check the two organisations, which according to Cresswell and Miller [40] enhances the validity of the data that is collected.

\subsubsection{Organisation A}

Organisation A is located in a former pit (coal mining) village dominated by two public housing estates. The village is comprised primarily of three lower level super output areas (LSOA), two of which are within the top $10 \%$ of highly deprived areas in the UK and the third in the top $20 \%$. There is a geographically larger more rural, area to the south of the village that is in the top 30\% of deprived areas according to the English Index of Multiple Deprivation (IMD). Organisation A offers a wide range of food-using activities that address the needs of a range of people within the village including social cooking and eating activities, an emergency food parcel service, a free food table, and a food pantry membership scheme. Organisation A utilises more than 50 volunteers and two staff to deliver these food services, as well as health and welfare signposting, free internet and computer access, low-cost printing and access to reduced cost energy supply among other things. The organisation began in the 1990s as a way to bring different small activity groups together to be able to give the community a political voice in the larger local authority and to be able to lobby for the wider community. It became a charity in 2002. Both staff and volunteers are mainly from the local area, with the director having grown up in one of the housing estates in the village. Projects are funded primarily through boot-strapping, voluntary activity, and grant funding. The organisation actively and effectively seeks financial, material and labour donations from businesses and community members. It collects surplus food from food producers, stores and restaurants directly as well as subscribes to a national food surplus redistribution network. Bootstrapping involves using existing resources from within the community, e.g., piggybacking activities that are unfunded onto activities that are funded.

Throughout the three years of the research, a number of data collection activities were conducted with Organisation A. These included a guided walk of the area with a local authority social welfare team representative. A short-term research assistant was embedded within the organisation and participated in weekly activities over the course of three months. She kept a field diary of these activities. Six months into the project, two focus groups were held with residents who used the services, each lasting just over an hour and which I ran but were also attended by the research assistant who took notes. These focus groups were also recorded and transcribed. There were six participants from the community at each focus group. Participants were recruited by the researcher and through a poster that was displayed at the community centre where organisation A is located. The focus groups focused on food availability including food sources that may be less visible (e.g., schools, family meals, allotments, wild-food, etc.) and village life. Participants were also asked to reflect on their strategies for food procurement and general food practices. In keeping with the intention of enabling participants individual and collective priorities and experiences to be at the fore, conversations were loosely structured and wide-ranging rather than closely scripted [41]. Discussions addressed kitchen size and 
tools available, financial demands from school cooking activities, allotments, freezing, cooking and family schedules, out-of-village and in-village shopping, the lack of a market, food practices during the miner strikes, family eating and so forth. Participants were not paid for their time, but there was a prize draw for a $£ 20$ gift certificate given out to one participant. At the start of the project, an initial interview with the director of the organisation was conducted by the research assistant, but I followed-up with an additional interview lasting an hour and further interviews at six monthly intervals thereafter, which took place within the organisation. These visits also included participant observations of activities, including casual conversations with community members. The miner's strikes in the UK referred to here were a major industrial action between 1984 and 1985 and shut down the British Coal Mining industry in an attempt to prevent colliery closures. The planned closures are seen by many as an attempt by then Prime Minister Margaret Thatcher to reduce the power of the labour unions in the UK. In the last visit, in addition to interviewing the staff, I conducted further shorter and more informal interviews with volunteers and parents attending two children's activities and the subscription food pantry. Questions focused on perceptions of community need, the activities themselves and the benefits accrued as a result of participation. All recorded interviews were transcribed and coded as were field diary notes.

\subsubsection{Organisation $B$}

Organisation B provides many points of similarity and contrast that help to avoid confirmation bias within the research and indicate locations of learning [39], which are discussed in the results. Organisation B is the charity arm of a commercial food retailer and runs five purpose-built community hubs across England. All offer the same core services, which consist of a discount food shop, a kitchen, a café, a learning centre and a garden. Locations for the community hubs are chosen based on their high ranking in the Index of Multiple Deprivation. In addition to deprivation status, such as the village of Organisation A, both locations are former pit villages that were involved in miners strikes in the mid-1980s. The organisation is directed by someone who is not from the community being served, who is professionally trained to provide support and has extensive experience of working in a range of organisations seeking to help low-income communities. Alongside the management team based in the company headquarters, hub employees consist of community leaders identified through participation in the learning activities who live in and are members of the community. There are also paid employees from the community to staff the shop and the café and help run the learning modules, which also involves collaborating with outside originations to address community-identified learning support need. Like Organisation A, this organisation makes space for and encourages those within the community to organise events such as craft activities and walking clubs. Membership is required to access the food and the activities, although this is not fee-based but is based on economic and residential criteria.

Because the structure of Organisation B is multi-sited, data collection involved visiting two of Organisation B's community hubs in the north of England on several occasions. During these visits I observed activities as they happened and causally talked to staff and community members. I also conducted multiple interviews throughout the project duration with the director of the commercial enterprise that provided the funding to establish Organisation B and the director of Organisation B. I also conducted shorter interviews, each lasting between fifteen and thirty minutes, with the paid employees and some community members. Not all the interviews were recorded, but when this was the case, detailed notes were taken. In the summer of 2018, I participated in a week-long work-shadowing activity with the director of Organisation B. This work-shadowing involved participating in the activities as they occurred in the two locations as well as observing and participating in meetings with potential external partners and working through the design of a possible new program involving a delivery scheme. Field notes record the work shadowing and focus on what and how activities are done by the organisation. 


\subsection{Additional Data Collection}

To enhance the explanatory capacity of the case study data and to gain a better understanding of food insecurity and how it is being addressed in the UK, I conducted interviews with a range of organisations. These interviews lasted approximately an hour and participants include two directors of poverty-focused charities (one regional and one national), two charities offering food parcels through the franchise model located in the north of England and two organisations that provide a subscription food service that draws on pre-supermarket surplus (e.g., still in dated but short-dated). One operates as a community marketplace or shop, which is similar to that which is offered by Organisation A in that it allocates food according to categories for a fixed fee. The second provides a delivery service where for a small fee community members can collect three or four pre-packed bags from their community centre once a week. With both subscription services other non-food service providers attend the food collection sessions. A ride-along with the director of the bag scheme was also undertaken to understand better how the organisation delivered its services and how community members interacted with it. This also enabled several short conversations with community members about their perceptions of the service. This work was all undertaken by me. Again, when a recording was not practical or possible, extensive field notes were taken during discussions or immediately after. FareShare, the UK's largest surplus-to-charity surplus food redistributor, provided previously unavailable quantitative charity data, which offers a view of the broader UK food support landscape.

The research also included a day-long workshop with charity organisations from across the UK (including Scotland and Wales, but not Northern Ireland) and local authority public health representatives nine months into the project. The purpose of this workshop, in addition to triangulating findings from the ongoing data collection and help further direct inquiry, was to explore the specific assets and barriers faced by community organisations as they seek to address food insecurity and how they might collaborate with local authorities [30]. This triangulation is also supported by field notes taken by me at a national level 'food poverty' event that attracted participants from across England, Wales, Northern Ireland, and Scotland. I also participated in the development of a number of food or 'food poverty' action plans: Three in local authorities and one in a combined local authority all in the north of England. Finally, a twitter group interview, which asked for responses to the question: What do you wish those who have never lived in poverty understood about your life? This resulted in 35 responses from individuals who self-identified as having direct lived experience of poverty in either the UK. Most of these responses were from women with only six respondents identifiable as men. Three identified as teenagers with the rest adults. Two of the responses were from my immediate twitter network; the remaining respondents are second and third order connections. Instead of being used to make inferences on the population as a whole, the short twitter statements are best suited for triangulating what the interview and participant observation materials revealed. Triangulation searches for convergence among multiple data sources and is a validity procedure [40]. The twitter statements also help to find the boundaries between what is specific about the case study locations and the larger UK context, because while experiences were shared those responding were located in other communities across the UK. The tweets are included in this paper when they provide pithy quotations that sum up longer conversations and field note observations. They are used in the text only when there is further data from either the field notes or interviews that support their use. This strategy was chosen because the text of the tweets are a closer representation of the everyday experience of those living at the sharp end of poverty and austerity because they are written by those with direct experience of this context, compared to the paper author's summations within the field diaries. While it is possible that tweets may be 'fake', examinations of previous tweets by each respondent suggest that they are credible accounts.

\subsection{Data Analysis}

Data analysis adopted an inductive approach as the aim is to build theory concerning the context of neoliberalism, poverty, food insecurity and resilience building community self-organising. As such, 
it does not seek to test a hypothesis or to apply existing conceptual frameworks [42]. The analysis involved grouping the material into categories and involved two stages [43]. The first stage identified how people talked about food practices as they relate to poverty. This data was also analysed to understand how the pressures of austerity and welfare reform impinged on people's relationships with food beyond those that are linked immediately to access and affordability. This analysis provides a framework of the dimensions of food insecurity that considered the effects of neoliberal policy as it works through poverty to undermine community assets discussed in the first section of the results. The second stage of the analysis focused on how the food-based activities of organisations A and B shape community resources for resilience building and self-organisation as well as how these organisations themselves are positioned against the wider neoliberal contexts within which they are located and are discussed in the second part of the results. Digital coding software was not used. Instead, more traditional manual coding techniques were employed as much of data is from field diaries and is handwritten. Quotes were highlighted in the transcriptions and in the field diaries and then noted in an excel spreadsheet. This technique permitted the original material to remain in situ, while also allowing for comparison, triangulation and sorting for use in the first part of the analysis. For the second stage of the analysis, which focuses on the case study organisations, this approach enabled the data to be 'thought through' in order to build thick descriptions of processes that play out. Thick descriptions are deep and detailed accounts that provide readers with a sense of 'being there' and as a result helps to establish the credibility of the narrative [40].

Given the nature of the project, there are some further limitations to the data that readers should be aware of. The research primarily took place in villages that were neither inner-city areas nor very rural places. In all cases, the villages were relatively bounded and had some form of high street associated with them. A bus journey of some cost and duration was required if residents wanted to access food markets and other services in the nearby cities. Further research focusing on other geographies may reveal additional issues faced, for example for those who live in very rural areas where there is not immediate access to food and where neighbours may be distant or conversely where there is ready access to the public markets, a range of low-cost food outlets and support services. Housing estates in the case study organisation villages were low rise rather than tower blocks. The majority of research participants are white British ethnic origin because the organisations that were engaged for this research were primarily serving white-British communities. This research also does not consider how food insecurity plays out and resilience making practices are enacted in places or with households that are more financially affluent. The data analysis also suggested that there are other circumstances that give rise to food insecurity that may not be directly linked to poverty such as living with a disability or as an elderly person on their own, but these are not foregrounded in this paper, nor are the gender-related dimensions that were also evident in the data.

All subjects gave their informed consent for inclusion before they participated in the study. The study was conducted in accordance with the Declaration of Helsinki, and the protocol was approved by the Ethics Committee of the University of Sheffield (Project identification codes 007051 and 017298).

\section{Results}

The research sought to capture the practices that make up the context of food insecurity under neoliberalism as well as how the community organisations are working with their communities to help them to become less vulnerable and insecure. This part of the paper is divided into two broad sections. In the first section, the contours of vulnerability are discussed as they related to four dimensions of community resource depletion related to food insecurity that were identified through the analysis. It starts by considering how poverty impacts on individual and household food practices, which impacts on their relationship with food and has health effects and thereby diminish both food and good health as community assets as it also increases vulnerability to crisis. It then considers the physical and psychological implications that arise from the food insecurity-poverty nexus that undermine people's mental wellbeing and self-confidence as well as negatively shapes people's engagements with their 
neighbours and the places where they live. The section then turns to vulnerabilities at the community scale by considering how food insecurity materialises into the foodscape of the place. The section finishes by linking individualisation back to the capacity to self-organise. The second section shifts to the two case study organisations and how they are building resilience to these vulnerabilities and supporting capacity for self-organising.

\subsection{How Poverty and Food Insecurity Intersect}

At the minute prices are rising. The cost of living is increasing, and wages aren't very high, and it's just costing you more to live, and so you don't really tend to have a lifestyle or social life because you're that focused on accessing the food that you need to survive. (Organisation A, Coordinator)

That austerity impacts on everyday life in communities should not come as a surprise, and it is clear that welfare reforms coupled with austerity are a vital driver of an inability to purchase enough food to feed oneself and one's family consistently, sufficiently, and nutritionally [44]. People talked about the financial difficulties of having "more days in a month than money to cover them (field notes, November 2017)". Community organisation providers also talked about households in their communities that had a food budget of just fifteen to twenty pounds a week. Food-using charities revealed, that while these families may not be at crisis point, and therefore accessing emergency food, their diets still are not sufficient to meet the requirements of the national nutritional guidelines, which in the UK is known as the Eatwell plate [45]. Some forgo eating meals. For example, charity workers talked about families unable to provide breakfast, and who rely on extended family. The children have had to go to grandma's for breakfast because they did not have any bread (field notes, June 2018). People living on these tight budgets also talked about forgoing certain food items such as meat and fruits and vegetables. For example, one young woman who was interviewed said:

We rely a lot on frozen food. It is very hard to eat healthy meals. It's affordability more than anything. To buy fresh fruit and veg, each week. It goes off so fast, and you constantly are topping up. And you know it is expensive when you are buying strawberries at two pounds a go and fresh grapes at two or three pounds a go.

One food charity operator who provides cooking lessons described children who did not know what grapes were because the parents could not afford them. The manager of a surplus food pantry confirmed that people often did not know what the food that was on offer was or what to do with the food they receive because surplus food often includes items that would usually be well beyond the affordability of people on a very low-income (for example asparagus or whole fish).

People who were on very low-incomes in the communities also talked about difficulties with budgeting and being able to access the best deals and the cheapest food. While many organisations offer budgeting advice, it is clear that this advice is not always contextualised for the budgets within which many are operating, as exemplified by quotes from these two twitter respondents.

People tell you buying in bulk is so much cheaper in the long run. Look, there is no long run when you are living paycheck to paycheck. On top of that, I have no room to store this food before it goes bad.

And you go to the store planning to put that budgeting lesson to work. You read the signs and do the math. Which is the better deal? 500ml for $£ 3$ or 1 liter for $£ 5$ ? And then you think, well I only have $£ 3$, so I guess that answers that!"

While it is clear that people on low-incomes are aware of the advice, something also confirmed in the focus groups, and many are trying to integrate it into their spending, the savings to be achieved through good budgeting is beyond their capacity. As such, there is a premium that must be paid when your budget does not stretch to the level where the discount becomes available [44]. One focus group respondent summarised this by saying, "Poverty charges interest", which is becoming even more literal as food bank providers report people are increasingly using credit to buy food [46]. 
For the households in this study, thrift is central, and they dare not buy some foods for fear of it going wasted as hinted in the earlier quote about strawberries and echoed in this quote from one of the residents of Organisation A's village.

You just can't get them (vegetables) as regularly as you want. I think the vegetables around here are too highly priced compared to what we can get elsewhere, so it is very rare that I buy veggies in the village. When we were chatting in here yesterday, somebody was saying, "Oh, I hate buying fresh carrots because as soon as you take them, they go black."

Throwing away food items is equated to throwing away money, which is already in short supply. As a result, risk aversion becomes part of the process of food procurement, which is also a set of calculations that take a mental toll as this twitter respondent articulates, "Every purchase is a mental calculation, and it is exhausting (see also [29])." These food calculations materialise as purchases, for example of frozen and processed foods because they last longer and as such are better value for money. In addition to the mental stress of having to avoid wasting money, there is also the potential health costs associated with a diet lacking in fresh fruits and vegetables. These pressures become more pronounced for many of these families when the school holidays arrive, and access to free school meals are no longer available [47].

The inability to buy food to feed oneself or one's family has knock-on effects for physical and psychological health because it introduces tradeoffs over spending priorities both in terms of the food choices that are made but also in terms of decisions to address other household needs that may arise, which can also lead to crisis [44,48-51]. The data show that the complexity of having to make spending decisions that have direct and indirect relationships with being able to eat or being able to eat a healthy diet, unsurprisingly not only damages the relationship one has with food but also impacts on one's relationships with others. Poverty has implications for the social networks that people who are on low-incomes can maintain, which in turn compromises the social cohesion of the communities where they live.

Research on social networks demonstrates that those who have strong social networks live longer and better lives, even when they are living with ill health $[52,53]$, but as respondents demonstrate engaging in social activities that enable networks to flourish is linked to being able to afford to participate in those activities. Without funds to participate, social networks break down and isolation results. For example, one resident in the village where Organisation B is located illustrates how isolation is linked to poverty when he says, "Everything about social interactions requires money. It takes money for the bus, for the drinks, for the texts to organise a time. Before I came up here, I would hardly leave the house." A twitter respondent confirms this issue and links it back to the mental states and the ability to take risks.

The chronic stress of poverty affects everything - your relationships, your ability to make decisions, your ability to focus, your ability to regulate your emotions. It also restricts your freedom because accidents that might not be a big deal for others would ruin your life. It is a constant, bone-deep, live-with-it-so-long-you-don't-know-it's-there stress.

The director of Organisation A ties this isolation directly back to the vulnerabilities of food insecurity:

Families in (the village) struggle to pay for food and have an activity that entertains the kids on a long break such as the summer. It's kind of like meet or eat. You either pay for something to feed your bellies, or you pay for something to keep your kids entertained.

Residents in her village are forced to choose food over social activities, which in turn results in social isolation for parents. Additionally, if the parents let the children play on the street, there is the threat of violence or the potential that the children will act in ways that cause trouble for other residents because there is nothing for them to do. For example, one of the volunteers with Organisation A talked 
about the feelings of fear that some of the parents had of doing things with their children in the parks that are nearby, "A lot of mums won't take the kids out, it's just down to the reputation (of the place) which is unfortunate." The village becomes a site of fear which leads to further isolation and a devaluing of the community spaces as an asset to be used for self-organising.

The causes of fear are multiple. Some of the reason for this fear was elaborated by a volunteer with Organisation A who said: "you've got these little rogues running the streets. There is not a lot for them to do in (the village) so they get up to all sorts." People from both organisations also talked about children's anti-social behaviour as being linked to the loss of physical infrastructure in the villages which included the loss of council-funded family and children's centres, the closure of libraries, and the closure of local markets. The staff of Organisation A also identified the way in which this cycle of fear and isolation is further exacerbated by local authority housing strategy. They felt that there was also a large transient population, which they identified as people who had been released from prison and then rehoused in the village; "They are not from the village, but are put into the village." They felt that those making the housing decisions for transient groups viewed the village as a problem already, and "throwing a few more into the mix was not going to make a lot of difference." Both staff felt that this policy increased isolation because it divided the community between those who were part of the mining tradition and these new populations that had no shared history. Rather than building social capital by mixing groups [54], this housing strategy undermines the connectivity of the existing residents by driving them into their homes. It is not just individuals who suffer when people become isolated from each other and fear the places where they live; the place of the community also suffers.

Practices materialise into places as is illustrated by the communities in this research [1,55]. Food insecurity emerges in a context where the individual food preferences of household members are imbricated with a broader commercial context dominated by food producers competing for stomach share by emphasising personal choice and taste over nutrition. The stress of poverty in this structural context can lead to circumstances whereby food itself becomes a site of conflict to be minimised and avoided, not something to be enjoyed, let alone shared if indeed sharing is even affordable. Research on food practices demonstrates that the emotional relationship one has with food shapes how cooking and procurement practices are enacted [56,57]. In a local place where the majority of people are experiencing negative food associations, the commercially driven food landscape comes to reflect the food purchasing patterns that are the result of these emotional negativities, household conflicts, and commercial forces (for a related argument see [58]).

Like many poor neighbourhoods across the UK, the villages where Organisation A and B are located have many empty shops and an abundance of cafes and takeaway restaurants providing low-cost food items. In a focus group with participants from Organisation A, the foodscape was described in terms primarily of absence and loss particularly highlighting the closure of the local market and children's centre. At the same time, in the supermarket, the food items that are wanted are not available as one resident of the village where Organisation A is located explains:

We don't have one of the big (large chain) stores here, just a small one, and in my opinion, it is more expensive. They don't carry the value stuff. They've got rid of it. If we want it, we have to have it delivered. I think it is because they don't make enough profit in the store (when the value ranges are available) because everyone takes the value stuff and leaves all the rest.

One of the members of Organisation B talked about the way this foodscape has knock-on implications for the ways that people interact with each other, which also links back to the social isolation discussed above and undermines the capacity to self organise and be resilient to shock.

It is awful if you walk up the front street now it is dead. There is nobody about. The banks have shut down; various shops are shutting down. There is nought here. People are having to go get food parcels and things from the Salvation Army. I really don't think that this day and age it should be like this. You can walk down the street, and people are scared to even smile at each other or say hello anything like that. There is so much violence. It makes people wary of each other. There is nothing preventing 
this, with the government cutting back on a lot of things, youth club and play areas, they have all been shut down.

This quote points directly to policy, but it, along with the much of this narrative also highlights the effects of these policies across scale.

The contrast to previous time periods is clearly demonstrated when one considers how people talked about a sense of community in the village at the time of the miners' strikes and before when there was poverty, but also a greater sense of community collectivity. Many participants reflected on going to the pits with their parents and taking part in community activities. This formed a basis for support once the mining pits closed. For example, one village resident reflected on the period just after the miners' strikes:

And if you look at my mum's side of the family, there was seven of those. So there were aunts and uncles and there were partners that just couldn't work. I remember them coming ... I'm about 10 at this time. So I started understanding emotions in the world a bit better than sort of a younger person ... But they'd all come to each others' houses with ingredients for food. And they'd have a big pot of something. So my mom might bring 'taties (potatoes). Aunt Marie might provide the meat or my grandad brought rabbits into the house and we would all eat together, aunts, uncles, cousins, grandparents.

When this is reflected against the quotes above it is clear that the effects of food insecurity are not just produced by state economic policies that play out through household budgets but are also written into places through the ways that social systems and practices organise and reproduce each other within the wider context of those policies.

Sustained vulnerabilities are not just the result of isolation, lack of individual confidence, a dearth of strong social networks and the absence of built infrastructures, they are also a result of the creation of a context whereby self-organised social change is also suppressed as a result of a much longer trend in the way the UK governmental policy and intervention has treated these households and communities. The director of Organisation B described this as a more entrenched process, extending back before austerity was introduced.

While we have had certain shocks as a result of austerity and changes to welfare, I think there has been longer term deskilling. People have been taught not to think for themselves and to feel confident that they can group together to address issues in their communities. People have been isolated and atomised and have become dependent first on the state to solve their problems then by neoliberalism to feel that they are isolated and cannot depend on their neighbours.

What this quote also highlights is that a solution that focuses just on rolling back welfare reforms, while important, is not going to be sufficient if other more transformative aspects of resilience are to be fostered. The damage of poverty requires more than direct national scale poverty alleviation.

\subsection{Building Self-Organising Capacity to Confront Food Insecurity}

This section analyses the ways in which community organisations, through food activities, help build different forms and levels of community resources that lead to self-organised resilience in the face of food insecurity. This research identifies these resources as finance and infrastructure, diet diversity, mental health, social networks and community cohesion. While research on food support has tended to focus on individual food services with the majority of research focusing on the food parcel [14,59,60], FareShare [61] statistics indicate that food support within the UK is quite extensive and diverse. Organisations that provide other food-related services such as those offered by both Organisation A and B are less easy to identify, compared to food parcel providers as there is no registry. The network of charities that FareShare provides with access to surplus food extends across the whole of the United Kingdom either through an app-enabled back of store collection service (approximately 6962, charities) or via distribution through one of the 21 regional FareShare warehouses (3195 charities). 
Approximately $77 \%$ provide meals (social eating), $57 \%$ offer snacks (social eating), $58 \%$ give a food parcel (social distribution), 25\% run a pantry (social distribution), and 33\% conduct cooking lessons (social making and/or learning). Only one-quarter of the charities offer a single food service, with meals the most likely service provided on its own (18\%) and only $8 \%$ provide an emergency food parcel on its own.

Both Organisation A and B operate within a model of multiple food provision. While those who use surplus food via the FareShare network are a significant number, this number is also not likely to capture the whole of the UK food support landscape, as there are organisations that use other means for securing the food that they provide through their services, for example Charity B or those who offer food parcels by purchasing food and/or with publicly donated food. Charity A also buys food and receives public donations to support its food services. The remainder of this section starts with Organisation A and then moves on to Organisation B before making some comparisons between the organisations.

Over the course of the interviews, the director of Organisation A talked about each service they offer and how it had begun as a result of something they noticed within the community. This is in keeping with the ethos behind its conception as an organisation that would seek to bring different groups together to address local need. The initial focus of their food-using activity was not to help residents access food in an emergency or to enable access to food; this came later as people within the village began to be moved onto Universal Credit. They started with snacks and shared meals because they noticed that many of the elderly within the community were lonely and were visiting the local medical centre in order to be around other people. As a result of putting on a craft activity, which included a cup of tea and a snack, they reported the number of medical visits by older people in the village went down. The director described an 86 year old volunteer who has now taken over the 'crafternoon' sessions.

She was working in a café, but once that closed, she felt a bit lost. She was forcing herself to go buy a paper because that meant she got out every day. She won an award for her volunteering and when she got up to thank everyone she had us all in tears saying how much it had changed her life. How she was really low, she did not think that she'd see her next birthday, and then coming here had totally changed all that.

These crafternoon sessions facilitate social connections and a sense of purpose for older residents in the community, which has the outcome of enabling them to live longer and better lives [50,51] but also makes them available as a motivated resource for community self-organisation.

Organisation A added cookery lessons after staff attended a team building course. In the team building, they had to go to the local shops and buy items to cook a three-course meal on a tight budget. Based on this course they felt that this would be something that they could bring back to the community. In the first interview in 2016, the coordinator talked about the process once they decided to offer cookery activities.

Now we facilitate a six-week cook and eat session called 'healthy, wealthy, and wise' where we do five weeks of different recipes, mostly fake-aways because that is what people like to eat around this area ... sort of like healthy burgers and healthy KFC. This is all with basic equipment. We play icebreaker games and give them a choice of recipes to decide what they are going to cook, and then they go off and cook it, and everyone sits together and eats. We try to get the kids involved as well.

The aim behind these courses is to find a fun way for people to learn to cook healthy options within a tight budget.

Residents (primarily women) talked about the difficulty of getting family members to eat fruits and vegetables but reported that when trying the recipes at home, they were able to "hide" these items in food that looked familiar. Many spoke with a sense of pride at being able to provide healthy foods for their families that they would eat and enjoy. By enabling new ways of cooking these cook and 
eat sessions also reduce some of the stress associated with trying to find low-cost food that families will eat that are also at the same time healthier options. Staff also said that by building on existing food skills participants began to be more confident and have more positive relationships with their food. This intervention also expanded the reach of their services to a wider range of age groups in the community thereby enhancing the communities capacity to build resilience.

As austerity and the transition onto Universal Credit began to affect village residents more deeply, they added a free surplus fruit and vegetable table for anyone in the community with a hot lunch on the side.

We heard horror stories from the local landlords telling us there are some people who don't even have pans, so it is obvious that they are not cooking any sort of meals. It would be sort of a bag of crisps on the way home from school. (school lunch) would be (the children's) main meal. The parents would not have much more than crisps.

While residents clearly benefit from access to this food, so do the volunteers, and a greater number of food-services not only attract more people but also provide a way for them to give back.

The lunch and food table is run by older female volunteers, many of whom the director described as being near the end of their working lives, but because of benefits reforms are being required to find new employment after a job loss. By volunteering these women are meeting a psychological need to be working and not feel dependent. The director said:

Many are two years off retirement and being forced to sign on for work when they had never had a CV in their life, and they don't know how to use a computer. They feel that by volunteering, that will support what they are given. They all want to find work because they have grown up working. Some of them have been out of work for a few years and have lost their confidence. Looking at their age, I don't think people will employ them again.

While these women may not ever find paid employment, the time they spend supporting their community is also enabling them to feel better about themselves. The reciprocal arrangement helps them to feel not as though they are receiving a handout, but instead are part of a group offering mutual support.

The food parcel service began in 2016. The staff spoke about people who needed some support because they had been referred by the benefits service to receive a food parcel but could not get to the town centre where the parcels were being handed out, or it was not open on the day it was needed (e.g., parcels were available on Tuesdays only, but the need arose on a Thursday; or over the holiday period). They talked about a family where the husband had been diagnosed with cancer, and his wife could not run the shop alone and take care of him but did not have any benefits sorted to take up the slack. They wanted to offer support that was local that would enable people to get help when and where it was needed.

DeVerteuil [11] argues that this kind of support enhances the ability to absorb disturbance. The protective care offered by emergency food support enables a getting-by and getting on. The food and the conversation that the staff and volunteers provide to those collecting parcels can provide a pause or resting place away from the storm and struggle that comes alongside everyday food insecurity [13]. While this support can offer a moment of repair, these emergency interventions are also always infused with a particular power relationship whereby one participant is always the giver, and the other is always the receiver [18]. Observations of those accessing the parcels revealed how people kept their heads down and kept to themselves rather than interact with others, despite efforts by the providers to limit the feelings of embarrassment and stigma. A few of those who received food parcels did go on to become more involved with the organisation through volunteering, but not many. As such the multiple dimensions of resilience building that involve more than coping by enhancing social networks and building confidence do not seem as likely to be an outcome of organisations that offer only an emergency food parcel. 
In 2017, Organisation A started offering a pantry service where for a small fee people could access fresh food. The organisation staff felt that food access was needed by people who were not in crisis, but still vulnerable to food insecurity and is also a position taken by many who provide this kind of food support. The director explained:

It stemmed from the support from the food parcel, it enables people who were finding that in some circumstances they did not need the free support, but they were still struggling to fill their bellies. So we offered the cupboard. It is sort of the next step. We have had people who have left and said we don't need it any more now that we are alright. As much as we want the community cupboard members to step away because of being in a better position, I think there is going to be more demand for new cupboard members than ones filtering back into mainstream supermarket shopping.

The observation that the financial situation for households in the community is not likely to improve is a salient one. However, some are able to move on.

While income and financial need were the key motivation for providing this food service and community members talked about how the access abled them to "live from week to week", the organisation is finding that the pantry is enabling better relationships with food to form, food knowledges are expanding, and people are less risk-averse. Quotes from the director and a staff member illustrate this point:

Kids come along now with the parents to do the shops and the kids have the choice of what food that the mum or dad wants to buy out of the cupboard. It is giving the kids more overall responsibility with what food that they can try because the parents haven't got the pressure over whether or not they can afford to not like it. (Director, Organisation A)

So I think it has changed how they cook as well. They get a different thing every week, so they try new foods and they have a completely different way of cooking. To be honest, a lot of people from (the village) wouldn't have even looked at an olive, never mind tasting one. They have tried them and come back and they love them. They are on low incomes, so they are not going to buy the more expensive food in the shop. Here they have a chance to try different things. (Staff, Organisation A)

The pantry is affording nutrition and food security resilience. It, along with the cook and eat activities is changing the understanding of what counts as food in the community, and thereby reducing reliance on a very narrow range of food items. As new-to-the-community food items are offered, conversations about this food are bringing people together.

While the different food-focused activities being provided address the immediate issues of hunger and the financial aspects associated with being able to afford food, there is also a clear narrative of how food-using activities are helping people to overcome feelings of isolation and lack of self-esteem. By offering activities in combination, Organisation A is enabling people to be both givers and receivers. The quasi-market exchange in the pantry is also enabling interactions that are not present in the gift-exchange of the food parcel. The better relationship with food lends itself to an ability to play, experiment and try new things that broaden food horizons, and also opening the door to the possibility of wider collective social transformation within the village.

The ripple effect of being able to give and take, building up of social networks, and having the opportunity to contribute is also helping people to feel that they are making a better community more generally. One of the volunteers is an older woman nearing retirement age. She spoke to us while working at a children's summer activity session put on by the organisation. She also is a member of the pantry scheme. One afternoon at a summer family bar-b-que put on by Organisation A, she described in important terms what this combination of support has meant to her and to the place where she lives:

Not only am I a trustee for (Organisation A) and a volunteer, I am also on the committee of the friends of (the local) Lake. And we work in conjunction with (Organisation A) so that they can have other activities here down by the lake. They have a teddy bear's picnic, lantern walks, and activities like 
this. I think we should bother. Because we are bothered and we are passionate about what we do it has turned not only this area around, but the whole of the community around. And allowing people to get involved in everything that we do. So yes, it is worth bothering with. And it just lifts people's aspiration; it has broken down barriers. What can I say? Community means everything, without a community you've got nothing. And yes, sometimes it is very challenging, But worth that challenge because the end result is fantastic.

These organically emerging activities have resulted in a food-using service hub that is responding to community need and building on community assets. One food using activity has begotten many more, which in turn has enabled Organisation A to expand its list of regular volunteers from twenty to more than fifty over the time that this research followed them.

There are synergies provided by offering multiple food activities. Individual activities are meeting different needs for different groups, e.g., older people through the snack and crafting, women (primarily) who attend the cook-alongs to find new ways to get their families to eat more vegetables, people in food crisis who need emergency food support, people who are just about managing, but not quite who benefit from the food pantry, the mums with children who are afraid to go out with them to the park alone. What is also clear from this narrative, is that there is crossover such that someone receiving support in one area goes on to be a volunteer in another area. An intergenerational transfer is occurring as older people help with crafting and cooking activities that happen during the school holiday events. Feelings of fear associated with the spaces of the community are breaking down, and people are connecting in meaningful ways with each other, just as they are gaining confidence in terms of what they can provide. Each activity contributes to an overall element of transformation acting on individuals and also the community as a whole. The diverse array of food activities are a scaffold that enables this community to be less vulnerable because of the way these food practices are helping to build a new foodscape on top of the one characterised by poverty, negative food associations, austerity and neoliberalism.

Organisation B is achieving similar ends but has approached this process somewhat differently and has been able to implement community-level change more quickly compared to Organisation A. The success is enabled by the fact that the organisation is supported by a very successful food business, whose owner is from the area where the two locations visited are located. This business has provided financial contributions, logistics and food access, which means that experienced staff could be hired, that jobs within the organisation are available, and that there is greater longer-term security than experienced by Organisation A. These resources also mean that Organisation B can operate as a CIC rather than as a charity, which eliminates its dependence on donations and grants for its continued operation. Shop sales sustain the costs associated with the other activities that are part of the hub. As such its status as self-organising at the organisation level is more ambiguous compared to Organisation A.

Rather than grow its services organically, the hubs were designed to provide a framework of services from the beginning aimed at enhancing both individual and community capacity. The organisation is viewed as a hub designed to be, according to the director, "a platform to empower and equip people to go out and be community change makers ... food gets them in the door." The director described the ethos of the food spaces within the hub:

We have a community kitchen, which is a café and a cooking space-not technically a cookery school because that sounds like we are teaching people to do that stuff and we don't believe that there is a requirement to do so. What there is a requirement to do is create a safe space where people can start to reconnect with food. Where people can start to articulate their own story in terms of their food history. ... To help people build confidence around food and to reconnect with food as a primary narrative for them to articulate who they are and to use it as a tool to bring their households and communities together and to have a bit of fun and celebrate. To make food and the preparation of food a massive moment of delight and where people feel an amazing experience of each other around food. And at the 
same time, we network with support organisations to help people identify what they are good at and where they could do a bit better, and we work on that together.

While evident in the way the director frames this quote [51], but which is not elaborated is the commitment that Organisation B has to an asset-based approach [6,7]. While the organisation starts by locating in a place that is identified as one that is highly deprived and targets those who are struggling with meagre incomes, the interventions focus on learning activities that aim to build and enhance the assets that already exist within the village and with the individuals and downplay the deficits [7]. According to the director this means "focusing on what is strong not what is wrong."

The ethos of using food to enhance feelings of self-worth and community connectivity is working as is illustrated by one of the community coordinators in Organisation B:

For me, it is seeing people progress. Seeing people coming in with no confidence, no self-esteem, no job, and they will come back, and it's like, especially the women, they might put a bit of make-up on, dress different, hold themselves different. Just difference in themselves and are proud and stand tall with their shoulders back. And people are helping each other and being there for each other. It is like where I live (in this community) compared to my sister-in-law (living in another community). She comes to my house and says the difference is if I want a cup of sugar I could knock on my neighbour's door across the road and she would have it for me there, or a slice of bread or ought like that, just basics. Down where she lives you don't get any of that, and they don't talk to each other. There is no communication. Here people lift you up not pull you down.

These feelings are translating into everyday actions of reciprocity and the longer term security of being able to trust one's neighbours, but also knowing that that burden of trust will not overwhelm [8].

The commitment to an asset-based approach is also the reason Organisation B does not offer emergency food. A food parcel was felt to be too wedded to deficit thinking to be included as part of the food offer. The director also recognises that to expect people who are in crisis to have the capacity to be community change makers is unreasonable. He said:

In crisis resolution there is a tremendous financial and psychological damage on an individual, so why not stop it before it can happen. (Organisation B) was positioned not to compete with those folks who are doing crisis stuff nor with those discounters running a great business selling cheap food, but to be a space in the middle. We see it as a progressional food ladder. That gives them a ... kind of breathing space where some of the very practical needs are met. People can then aspire to understand the journey that they want their life to take, put some plans in place, we can help them to start to deliver that and then they can move on. We try to provide people with a really simple way to understand that across a team, rather than within an individual, you have a greater ability to stack up the odds in your favour. Not only because of the stuff you know by having learned and grown as an individual, but also by having access to a wider network through which you will know the people that you need to know to help you best navigate that situation.

Through these interventions the organization provides a scaffolding to support the development of community assets.

An asset-based approach is also evident but less intentional in Organisation A. A key similarity is the notion of a ladder approach to support that sees people accessing food in different ways according to their circumstances, but which once their circumstances change also offer the next rung of support. Both organisations also report that on the back of interactions that have occurred while participants have engaged with the more social aspects of food support that are offered, new groups are forming, e.g., walking and singing groups, but a new community based self-organised weekly market.

Both Organisations A and B illustrate the power of bringing different food activities together to create opportunities for people to find common ground and to recognise and build the individual and group assets that are needed within their communities. These assets include time, skills, food stories, and food knowledges, which can be mobilised to build social networks that also become a community 
asset to be drawn upon in times of need, and involves providing a range of food-using activities. As a result, how resilience happens and transformations emerge are context specific but embedded within a wider context of constraints and possibilities linked to national scale policies and their local scale effects. Participants in both organisations argue that their communities are stronger and more resilient as a result of these interventions, compared to the period prior to their inception and compared to locations where such interventions are not being undertaken, but they also acknowledge the wider contextual difficulties.

There is an important contrast between the organisations that emerged. Organisation A, which is more obviously self-organising, is also more precarious compared to Organisation B as a result of different funding streams and organisational configurations. This organic adapting to conditions has also meant that it has taken Organisation A longer to implement the more transformative activities that were at the heart of how Organisation B operated from the begining. Where Organisation B intersects best with community self-organising is in the way that it has designed its interventions. Great care has been taken to ensure that as much as possible, people from the community are incorporated into and shape the daily practice of the organisation. In contrast to Organisation A, which is very much of the community, it may be some years, if ever, before Organisation B can fully shake off its position in the shadow of its sponsor and be fully community run and organised although this is the ultimate vision of its founders.

\section{Conclusions}

This research adopted a practice-theory informed approach to understanding how the resources needed for self-organised resilience building are undermined as low-income communities come into contact with neoliberalism. The main finding of this research is that there is a specific neoliberal context that increases the need for self-organising as a means of creating resilience capacity around food. This same context as it intersects with poverty also negatively impacts the self-organising process by reducing the availability of needed resources. The research demonstrates that neoliberalism has effects that arise in places as policies intersect with other forces and constraints that shape food insecurity. This, in turn, increases individual and community vulnerability to shock. The investigation of heretofore under-researched combinations of food-using activity demonstrates that community-based activity can shape local communities' capacities for the necessary self-organisation of their community resources, but this alone is not a sufficient condition for overcoming food insecurity. This relationship indicates that policy that focuses on self-organising is necessary, but not sufficient for enhancing resilience in low-income communities. Instead, a multi-scalar approach is needed that on the one hand redresses larger-scale policy that undermines resources and creates shocks in the first place. On the other hand greater support is needed at the local level that enhances the community-specific self-organisation capacity and resource needs.

The findings extend existing research identifying the impact of poverty on peoples' access to food and its nutritional content by demonstrating that the effects of poverty shaped by neoliberalism is not just limited to access and affordability. This research demonstrates people are not just hungry; they are also stressed, isolated and lack confidence. At the same time, communities and places are being hollowed out. As foodscapes and the relationships people have with food are eroded, so are the ways in which social connections are sustained. The loss of social connections is also figured into the places where people live. What were once community spaces become places of fear and isolation, which in turn undermines the capacity of these spaces to act as social infrastructures. This context undermines the food-related and food associated resources communities hold and that are necessary for self-organised resilience. Alongside financial resources health, wellbeing, social connections, peoples' relationships with food, local foodscapes, community cohesiveness and community infrastructures are all assets that support and are needed for community self-organising. Without these resources both households and communities are vulnerable to macro- (e.g., food price increases, changes in welfare 
provision), community- (e.g., loss of a food retailer or market) and micro-scale (e.g., the breakdown of a washing machine) shocks.

The research finds that self-organisation is more than merely free-time or hobby activity [8], its value for those facing food insecurity lies in its ability to help individuals and communities to be resilient in the face of the shocks. When Margaret Thatcher famously said in 1987 that "there is no society [62]" she was heralding individualisation [34]. Creating the conditions that enable self-organised community transformation challenges the individualising forces associated with neoliberalism. It does so by generating new conditions whereby social interaction and citizenship is not defined solely by one's ability to be a paying customer. This research argues self-organising is a capacity that must be learned and is something that can be facilitated through food-using interventions. It is clear from this case-study work that there are potential wins that self-organised community food activities can achieve that include enhanced personal wellbeing, increased social connections and increased place-based perceptions of safety if they are enacted in ways that enable these capacities to flourish. The successful self-organising in the case studies in this research aligns with asset-based approaches [6,7] that are underpinned by an ethos aspiring to community values and asset development, which builds on what is good rather than backfilling that what is missing.

These findings come with a word of caution. Self-organisation at the community scale takes a long time to reach its transformative potential and when community resources are deeply depleted, may never be achieved unless significant outside support is provided. Furthermore, policies that impose stressors on these fragile infrastructures, such as the parachuting of very transitory populations onto vulnerable places, undermine their foundations. The social and cultural capital that is developed by self-organisation is not necessarily going to be transferred to these new populations, and instead may be overwhelmed. Careful management of such situations is needed and for communities not to be left on their own to sort out issues locally by those who have yet to fully develop their self-organising capacities. Like Williams [8], this research cautions that policy rhetoric advocating community self-organisation as a means for community resilience must be careful not to impose the privilege of affluent populations onto deprived populations and then castigate them for their failure.

Finally, a policy approach that redresses the financial aspects associated with poverty such as the inability to purchase food is needed but is not wholly sufficient to address all the dimensions of food insecurity as it arises out of a context of neoliberal poverty. Rolling back welfare reforms may enable the avoidance of the immediate shocks imposed by the current economic system but does not address the collateral damage to area-based public health outcomes, the dissolution of social networks, and the hollowing out of communities that have also been the effects of wider neoliberal policy transformations. Individualisation has undermined the capacity for self-organising [63]. Therefore, solutions that seek only to eliminate financial deficits are falling into the neoliberal trap if they ignore the potential that food-based resilience practices offer. As developed in this paper, these practices provide a way to build skills that enable people to identify, connect with, utilise and enhance other community-based resources that may be as yet unrecognised, under-developed or otherwise diminished. Alongside this, a political economy that demands self-organisation is likewise insufficient if it does not also provide households with adequate resources for them to get by and community accessible, safe spaces with support to maintain those spaces. The next step is to consider how local and national level governments can help create the conditions whereby self-organising is allowed to flourish, without at the same time removing the safety nets that plunge people into immediate crisis and imposes longer-term damage on communities.

Funding: This research was funded by two Economic and Social Research Council Impact Accelerator grants, $\mathrm{R} / 145185$ and $\mathrm{R} / 155284$.

Acknowledgments: The author wishes to thank the organisations and all the participants who gave so freely of their time to this research. Thank you to FareShare UK for providing the quantitative charity data discussed in this paper. Georgina Gowans helped to collect some of the initial data for Organisation A. Thank you also to Adam Whitworth, Eric Olund, Jenny Pickerill, Moya Kneafsey, Mustafa Hasanov, Kim Wakelam, Lena Malkin-Lonergan 
and three anonymous reviewers for reading previous drafts of this paper and for your constructive comments. As the author of this paper, I take full responsibility for its intellectual content.

Conflicts of Interest: The author declares no conflict of interest. The funders had no role in the design of the study; in the collection, analyses, or interpretation of data; in the writing of the manuscript, or in the decision to publish the results.

\section{References}

1. Schatzki, T.R. The Site of the Social: A Philosophical Account of the Constitution of Social Life and Change; Penn State Press: University Park, PA, USA, 2002.

2. Hankcock, L.; Mooney, G.; Neal, S. Crisis social policy and the resilience of the concept of community. Crit. Soc. Policy 2012, 32, 3433-3464. [CrossRef]

3. Cretney, R. Resilience for whom? Emerging critical geographies of socio-ecological resilience. Geogr. Compass 2014, 8, 627-640. [CrossRef]

4. Bain, A.; Walker, A.; Chan, A. Self-organization and capacity building: Sustaining the change. J. Educ. Adm. 2011, 49, 7017-7019. [CrossRef]

5. Waldrop, M. Complexity: The Emerging Science at the Edge of Order and Chaos; Simon \& Schuster: New York, NY, USA, 1992.

6. Russell, C. Asset Based Community Development (ABCD): Looking Back to Look Forward: In Conversation with John McKnight about the Intellectual and Practical Heritage of $A B C D$ and its Place in the World Today; Nurture Development: Chicago, IL, USA, 2015.

7. Mathie, A.; Cunningham, G. From clients to citizens: Asset-based community development as a strategy for community-driven development. Dev. Pract. 2003, 13, 4744-4786. [CrossRef]

8. Williams, C.C. Socio-spatial variations in community self-help: A total social organization of labour perspective. Soc. Policy Soc. 2011, 10, 3653-3678. [CrossRef]

9. Aranda, K.; Hart, A. Resilient moves: Tinkering with practice theory to generate new ways of thinking about using resilience. Health 2014, 19, 3553-3571. [CrossRef] [PubMed]

10. Ziervogel, G.; Cowen, A.; Ziniades, J. Moving from adaptive to transformative capacity: Building foundations for inclusive, thriving, and regenerative urban settlements. Sustainability 2016, 8, 955. [CrossRef]

11. DeVerteuil, G. Resilience in the Post-Welfare Inner City: Voluntary Sector Geographies in London, Los Angeles and Sydney; Policy Press: Oxford, UK, 2015.

12. Glennie, C.; Alkon, A.H. Food justice: Cultivating the field. Environ. Res. Lett. 2018, 13, 073003. [CrossRef]

13. Blake, M. Landscape and the politics of food justice. In Routledge Handbook of Landscape and Food; Zeunert, J., Waterman, T., Eds.; Routledge: Abingdon-on-Thames, UK, 2018; pp. 4874-4899.

14. Loopstra, R.; Reeves, A.; Taylor-Robinson, D.; Barr, B.; McKee, M.; Stuckler, D. Austerity, sanctions, and the rise of food banks in the UK. BMJ 2015, 350, 1775. [CrossRef] [PubMed]

15. Garthwaite, K. Hunger Pains: Life Inside Foodbank Britain; Policy Press: Bristol, UK, 2016.

16. Poppendieck, J. The USA: Hunger in the land of plenty. In First World Hunger; Riches, R., Silvasti, T., Eds.; Palgrave Macmillan: London, UK, 1997; pp. 1341-1364.

17. Tarasuk, V.; Dachner, N.; Hamelin, A.-M.; Ostry, A.; Williams, P.; Bosckei, E.; Poland, B.; Raine, K. A survey of food bank operations in five Canadian cities. BMC Public Health 2014, 14, 1234. [CrossRef] [PubMed]

18. Riches, G.; Silvasti, T. (Eds.) First World Hunger Revisited: Food Charity or the Right to Food? 2nd ed.; Springer: Basingstoke, UK, 2014.

19. International Monetary Fund. World Economic Outlook. Database; International Monetary Fund: Washington, DC, USA, 2018. Available online: https://www.imf.org/external/pubs/ft/weo/2018/02/weodata/ (accessed on 24 April 2019).

20. House of Commons. Poverty in the UK: Statistics. Government Briefing Report; House of Commons Library: London, UK, 2018. Available online: https://researchbriefings.parliament.uk/ResearchBriefing/Summary/ SN07096 (accessed on 26 April 2019).

21. Loopstra, R.; Reeves, A.; Tarasuk, V. The rise of hunger among low-income households: An analysis of the risks of food insecurity between 2004 and 2016. J. Epidemiol Community Health 2019. [CrossRef] [PubMed]

22. Casstree, N. Neoliberalism and the biophysical envrionment 1: What 'Neoliberalism' is, and what difference nature makes to it. Geogr. Compass 2010, 4, 17251-17733. [CrossRef] 
23. Casstree, N. Neoliberalising Nature: The Logics of Deregulation and Reregulation. Environ. Plan. A Econ. Space 2008, 40, 1311-1352. [CrossRef]

24. Harvey, D. Neoliberalism as creative destruction. Ann. Am. Acad. Political Soc. Sci. 2007, 601, 214. [CrossRef]

25. Beatty, C.; Fothergill, S. The Uneven Impact of Welfare Reform: The Financial Losses to Places and People; Sheffield Hallam University Centre for Regional Economic and Social Research: Sheffield, UK, 2016.

26. Jones, G.; Meegan, R.; Kennett, P.; Croft, J. The uneven impact of austerity on the voluntary and community sector: A tale of two cities. Urban Stud. 2016, 53, 20642-20680. [CrossRef]

27. Gray, M.; Barford, A. The depths of the cuts: The uneven geogrpahy of local government austerity. Reg. Econ. Soc. 2018, 11, 5415-5463. [CrossRef]

28. Calver, T.; Wainwright, D. How Cuts Changed Council Spending, in Seven Charts; BBC: London, UK, 2018. Available online: https://www.bbc.co.uk/news/uk-england-46443700 (accessed on 1 May 2019).

29. Stenning, A. Feeling the squeeze: Towards a psychosocial geography of austerity in low-to-middle income families. Geoforum 2018. [CrossRef]

30. Blake, M. Feeding Affordances and Decent Helpings: Working Together to Reduce Food Poverty and Improve Public Health; University of Sheffield: Sheffield, UK, 2017. [CrossRef]

31. Barnard, H. End the Benefit Freeze to Sop People Being Swept into Poverty; Press briefing; Joseph Rowntree Foundation: London, UK, 2019. Available online: https://www.jrf.org.uk/report/end-benefit-freeze-stoppeople-being-swept-poverty (accessed on 1 May 2019).

32. Jupp, E. Families, policy and place in times of austerity. Area 2017, 49, 266-272. [CrossRef]

33. De Bruijin, E.; Gerrits, L. Epistemic Communities in Urban Self-organization: A systematic review and assessment. J. Plan. Lit. 2018, 33, 3103-3128. [CrossRef]

34. Castree, N. Neoliberalism and the biophysical environment: A synthesis and evaluation of the research. Environ. Soc. 2010, 1, 54-55. [CrossRef]

35. Alkon, A.H.; Agyeman, J. Introduction: The food movement as polyculture. In Cultivating Food Justice: Race, Class, and Sustainability; Alkon, A.H., Agyeman, J., Eds.; The MIT Press: Cambridge, MA, USA, 2011; pp. 1-20.

36. Blake, M. Building an unjust foodscape: Shifting governance regimes, urban place making and the making of Chinese food as ordinary in Hong Kong. Local Environ. 2018, 23, 1047-1062. [CrossRef]

37. Herman, A.; Goodman, M. New spaces of food justice. Local Environ. 2018, 22, 1041-1046. [CrossRef]

38. Sayer, A.; Morgan, K. A modern industry in a declining region: Links between method, theory and policy. In Politics and Method: Constrastng Studies in Industrial Geography; Massey, D., R Meegan, R., Eds.; Methuen and Co, Ltd.: London, UK, 1985; pp. 1331-1355.

39. Flyvbjerg, B. Five misunderstandings about case-study research. Qual. Inq. 2006, 12, 219-245. [CrossRef]

40. Creswell, J.W.; Miller, D.L. Determining validity in qualitative inquiry. Theory Into Pract. 2000, 39, $124-130$. [CrossRef]

41. Gibbs, A. Focus groups. Soc. Res. Update 1997, 19, 18.

42. Strauss, A.; Corbin, J. Basics of Qualitative Research; Sage: Thousand Oaks, CA, USA, 1990.

43. Saldaña, J. The Coding Manual for Qualitative Researchers; Sage: Thousand Oaks, CA, USA, 2015.

44. O'Hara, M. Austerity Bites: A Journey to the Sharp end of Cuts in the UK; Policy Press: Oxford, UK, 2015.

45. Lloyd, S.; Lawton, J.; Caraher, M.; Singh, G.; Horsley, K.; Mussa, F. A tale of two localities: Healthy eating on a restricted income. Health Educ. J. 2011, 70, 485-486. [CrossRef]

46. Davies, S.; Finney, A.; Hartfree, Y. Paying to Be Poor: Uncovering the Scale and Nature of the Poverty Premium; University of Bristol, Personal Finance Research Centre: Bristol, UK, 2016.

47. Machin, R.J. Understanding holiday hunger. J. Poverty Soc. Justice 2016, 24, 3113-3119. [CrossRef]

48. Garthwaite, K.A.; Collins, P.J.; Bambra, C. Food for thought: An ethnographic study of negotiating ill health and food insecurity in a UK foodbank. Soc. Sci. Med. 2015, 132, 38-44. [CrossRef] [PubMed]

49. Hall, S.M. Everyday family experiences of the financial crisis: Getting by in the recent economic recession. J. Econ. Geogr. 2015, 16, 305-330. [CrossRef]

50. O'Neill, T.; Jinks, C.; Squire, A. “Heating Is More Important Than Food" Older Women's Perceptions of Fuel Poverty. J. Hous. Elder. 2006, 20, 95-108.

51. Hall, S.M. Personal, relational and intimate geographies of austerity: Ethical and empirical considerations. Area 2017, 49, 303-310. [CrossRef] 
52. Dunbar, R.I.M. Breaking bread: The functions of social eating. Adapt. Hum. Behav. Physiol. 2017, 3, $198-211$. [CrossRef]

53. Cattell, V. Poor people, poor places, and poor health: The mediating role of social networks and social capital. Soc. Sci. Med. 2001, 52, 15011-15516. [CrossRef]

54. Putnam, R. The Prosperous Community: Social Capital and Public Life. The American prospect. 1993. Available online: http://www.prospect.org/print/vol/13 (accessed on 17 March 2019).

55. Massey, D. For Space; Sage: Thousand Oaks, CA, USA, 2005.

56. Blake, M.K.; Jody, M.; Lucy, C. Buying local food: Shopping practices, place, and consumption networks in defining food as "local". Ann. Assoc. Am. Geogr. 2010, 100, 409-426. [CrossRef]

57. Miller, D. A Theory of Shopping; Polity Press: Cambridge, UK, 1998.

58. McClintock, N. From industrial garden to food desert. In Cultivating Food Justice: Race, Class, and Sustainability; Alkon, A.H., Agyeman, J., Eds.; The MIT Press: Cambridge, MA, USA, 2011; pp. 89-120.

59. Cloke, P.; May, J.; Williams, A. The geographies of food banks in the meantime. Prog. Hum. Geogr. 2017, 41, 703-726. [CrossRef]

60. Downing, E.; Kennedy, S.; Fell, M. Food Banks and Food Poverty; House of Commons Library: London, UK, 2014.

61. FareShare (Sheffield, UK). FoodCasting Survey; Internal Communication: Sheffield, UK, 2018.

62. Thatcher, M. 1987 as Cited in The Guardian, Key Comments from Britain's First Female Prime Minister. Available online: https://www.theguardian.com/politics/2013/apr/08/margaret-thatcher-quotes (accessed on 22 March 2019).

63. Sandel, M.J. What Money can't Buy: The Moral Limits of Markets; Macmillan: London, UK, 2012.

(C) 2019 by the author. Licensee MDPI, Basel, Switzerland. This article is an open access article distributed under the terms and conditions of the Creative Commons Attribution (CC BY) license (http://creativecommons.org/licenses/by/4.0/). 